\begin{tabular}{|c|c|}
\hline & \\
\hline &
\end{tabular}

SEÇÃO: APRESENTAÇÃO

\title{
Das possibilidades e usos da história ambiental, ou uma introdução ao dossiê temático "História e Ambiente"
}

On possibilities and uses of environmental history, or a presentation to the "History and Environment" thematic issue

Caio Flores-Coelho ${ }^{1,2}$ orcid.org/0000-0003-1515-9404 caioflorescoelho@gmail.com

\section{Paula Tatiane de \\ Azevedo ${ }^{1}$ \\ orcid.org/0000-0001-7482-3139 paulaaze@gmail.com}

\section{Lucas de Oliveira}

Klever $^{1}$

orcid.org/0000-0001-5376-9014 lucas.oliveirag5@edu.pucrs.br

Recebido em 11/08/2020. Aproado em 10/11/2020.

\section{(c) (1)}

Artigo está licenciado sob forma de uma licença Creative Commons Atribuição 4.0 Internacional.
O tema do meio ambiente na pesquisa histórica e a preocupação com discussões socioambientais foram especialmente fomentados a partir da década de 1970. Alguns exemplos podem ser aqui apresentados, tal como a publicação do volume especial Histoire et Environnement na revista francesa Annales - Économies, Sociétés, Civilisations (ano 29, n. 3. 1974) organizado por Emmanuel Le Roy Ladurie e o curso de Environmental History na Universidade da Califórnia Santa Barbara, em 1972. por Roderick Nash (2014).

Dos anos 1970 em diante, temos um aumento exponencial do debate público de diferentes áreas do conhecimento sobre a ecologia (termo cunhado por Ernst Haeckel, em 1866) e o surgimento de diferentes movimentos políticos e culturais sob esse escopo. Como parte desses movimentos está o desenvolvimento de pesquisas com os mais diversos enfoques sobre a referida temática, mas que preservam a premissa de compreender o fenômeno histórico não somente a partir de seus agentes humanos.

Estas pesquisas vão desde a história ambiental de empreendimentos coloniais (BUBLITZ, 2008), a estudos que medem a gestão da água e o saneamento básico (RÜCKERT, 2015), ao motivo edênico no imaginário sobre a natureza do Brasil (CARVALHO, 1998), ao estudo do movimento ecológico e suas raízes no romantismo do séc. XIX (PADUA, 2005), até chegar nas mudanças climáticas e no Antropoceno (CHAKRABARTY, 2009).

Pensando nesse escopo, a Oficina do Historiador lançou, no fim de 2019, a chamada de artigos para um dossiê temático intitulado "História e Ambiente", direcionado a publicar pesquisas históricas que dissertam sobre impactos socioambientais gerados por processos de modernização, industrialização e urbanização, pesquisas que privilegiam biografias de pioneiros na área e investigações sobre relatos de viajantes e naturalistas, assim como relatos de interações entre diferentes agentes que tensionam a dicotomia Cultura vs. Natureza. 
Neste sentido, podemos ver que as possibilidades de pesquisa em história ambiental são vastas. Este dossiê publicado pela Oficina do Historiador traz onze artigos inéditos e uma resenha de livro. Esses artigos se referem a situações complexas que se desenvolveram ao redor do mundo, com especificidades muito diferentes entre si. Ao tratar do território brasileiro, traz-se pesquisas historiográficas desenvolvidas nas regiões da Amazônia, da Bahia, do Cariri cearense e, no Rio Grande do Sul, tanto no Alto Uruguai como no Vale do Sinos. Além disso, o presente dossiê traz ainda três casos transnacionais: da antiga União Soviética (Ucrânia e Bielorrússia), da Bacia Platina (Brasil, Argentina, Paraguai e Uruguai) e do altiplano boliviano.

O primeiro artigo do Dossiê é "Desastre nuclear, espaço e trauma: uma oração a Tchérnobil a partir de Svetlana Aleksiévitch" de João Camilo Grazziotin Portal, aluno de mestrado do Programa de Pós-Graduação em História da Universidade Federal do Rio Grande do Sul (UFRGS). Esse artigo traz uma interessante perspectiva sobre a hecatombe nuclear de 1986 na União Soviética ao fazer uma discussão sobre o espaço traumatizado das "zonas contaminadas" a partir do livro Vozes de Tchérnobil. E, ainda, ao trazer uma análise se valendo dos escritos de Hannah Arendt sobre as inovações tecnológicas da Guerra Fria, de algumas discussões da área da psicologia sobre trauma e do debate sobre o Antropoceno, já que a causa desse desastre ambiental foi a ação humana.

O segundo artigo é "Aportes de la Historia Ambiental para la Historia Agraria de la Cuenca del Plata, primera mitad del siglo XIX. Una propuesta pedagógico-didáctica" da Dra. Silvia Lilian Ferro, professora do Instituto Latino-Americano de Economia, Sociedade e Política da Universidade Federal da Integração Latino-Americana (Unila). O artigo traz uma revisão baseada na história ambiental sobre os processos históricos da primeira metade do séc. XIX na Bacia do Prata, especialmente, na justaposição entre a formação do sistema agrário e a organização política do periodo. Tem ainda como maior desafio a ideia de acrescentar o meio ambiente como um sujeito histórico que desempenhou papel relevante nas transformações da época, mostrando a possibilidade de se "ambientalizar" diferentes campos epistemológicos.

O terceiro artigo é "José Lutzenberger e a luta pela Amazônia: militância ambientalista internacional em defesa da floresta (1970-1990)", da Dra. Elenita Malta Pereira, professora da Universidade Estadual do Centro-Oeste (Unicentro), Me. Denis Henrique Fiuza, aluno de doutorado do Programa de Pós-Graduação em História da Universidade Federal de Santa Catarina (UFSC), e Sara Rocha Fritz, aluna de Graduação em História da UFSC. Esse artigo está inserido no projeto de pesquisa "José Lutzenberger: Um mediador entre o ambientalismo brasileiro e global (Déc. 1980-1990)", financiado pelo Conselho Nacional de Desenvolvimento Científico e Tecnológico (CNPq). Esse artigo aborda a militância ambiental de Lutzenberger. entre os anos 1970-1990, na defesa da preservação da Amazônia. Sua atuação e sua difusão da teoria de Gaia através de conferências, palestras e congressos foram de grande ajuda para trazer a emergência da situação da grande floresta para a pauta internacional, culminando com sua ascensão ao cargo de Secretário do Meio Ambiente no Governo Collor. O artigo aborda esses episódios e reflete sobre a trajetória do ambientalista através da biografia histórica e da história ambiental.

O quarto artigo é "Os impactos socioambientais e suas ameaças ao modo de vida das comunidades tradicionais de fundo de pasto na Bahia" da Me. Simone Conceição Soares Dias, aluna de doutorado do Programa de Pós-Graduação em História da Universidade do Vale do Rio dos Sinos (Unisinos) e professora da rede municipal de ensino de Monte Santo e da rede de ensino do Estado da Bahia. Esse artigo aborda a deterioração das terras comunais e de seu uso por comunidades tradicionais de fundo de pasto na Bahia, no bioma da caatinga, através da modernização e da expropriação dessas terras. O uso comum da terra entra em conflito com iniciativas extrativistas a partir dos anos 1970 e são parcamente amparados por legislação no Brasil, causando disrupturas em um modo de vida tradicional.

O quinto artigo é "Campos de experimentação 
agricola na Escuela-Ayllu de Warisata: reflexões sobre produtividade, trabalho e saber indigena no altiplano boliviano (1931-1940)", de Me. Bruno Azambuja Araújo, aluno de doutorado do Programa de Pós-Graduação em História Social da Universidade Federal do Rio de Janeiro (UFRJ). O artigo percorre a autobiografia de Elizardo Pérez, um dos fundadores da Escuela-Ayllu de Warisata, um projeto idealizado na Bolívia dos anos 1930 para utilizar a educação e os saberes indígenas para desenvolver a região do altiplano próximo ao lago Titicaca. Ainda, aborda as questões que emergem desse contexto através da memória biocultural indígena e do conflito entre as concepções dos indigenas locais e dos grandes proprietários de terra.

O sexto artigo é "Contradições entre a modernização agrícola e o desenvolvimento sustentável: o caso do Alto Uruguai Rio-Grandense - 1975-2017" de Me. Anacleto Zanella, aluno de doutorado do Programa de Pós-Graduação em História da Universidade de Passo Fundo (UPF). Esse artigo explora os Censos Agropecuários realizados pelo Instituto Brasileiro de Geografia e Estatística (IBGE) na região dos municipios gaúchos do Alto Uruguai, para analisar os processos de modernização da agricultura no Norte do RS no tempo presente e os impactos socioambientais advindos dessa transformação.

O sétimo artigo é "A história da coleta de resíduos em Novo Hamburgo, RS, e uma proposta de uma nova roteirização utilizando sistema de informações geográficas" de Natan Ruan Machado da Costa, aluno de Graduação em Engenharia Ambiental pela Universidade Federal do Rio Grande do Sul (UFRGS), Dr. Victor Fernandez Nascimento, professor no Programa de Pós-Graduação em Desenvolvimento Regional nas Faculdades Integradas de Taquara (FACCAT) e que realiza estágio pós-doutoral no Programa de Pós-Graduação em Sensoriamento Remoto da UFRGS, e Dr. Jean Pierre Henry Balbaud Ometto, pesquisador sênior do Instituto Nacional de Pesquisas Espaciais do Brasil e coordenador do Centro de Ciências do Sistema da Terra (CCST/ INPE). Analisa o aumento da produção de residuos sólidos urbanos na cidade de Novo Hamburgo na história recente, resultado do aumento popula- cional e do aumento do consumo de serviços. O artigo ainda traz uma proposta que busca compensar a emissão de gases estufa resultantes do processo de transporte desses residuos para o aterro sanitário utilizado pela Prefeitura, buscando aliar menores custos para manutenção da limpeza pública a um menor impacto ambiental.

O oitavo artigo é "O Cariri visto de baixo: movimentos camponeses em tempo de seca, fome, epidemia e recrutamento no Primeiro Reinado", da Dra. Ana Sara Ribeiro Parente Cortez Irffi, professora do Departamento de História da Universidade Federal do Ceará (UFC), e da Dra. Ana Isabel Ribeiro Parente Cortez Reis, professora de História na Universidade Regional do Cariri (URCA). Aborda a experiência de vida campesina na região do Cariri cearense, especialmente, através da seca dos anos 1825-1827, seguidas de um periodo de fome e de epidemia de variola, além do recrutamento de civis para a Guerra da Cisplatina. O enfoque "visto de baixo" do artigo permite ver a realidade de uma vida dura, da luta pela terra e do conflito de classes.

O nono artigo é "A ideologia verde e suas manifestações no Brasil na década de 1970" de Bruna Gorgen Zeca, aluna de mestrado do Programa de Pós-Graduação em História da Pontificia Universidade Católica do Rio Grande do Sul (PUCRS). O artigo traz uma relevante discussão sobre a formação da ideologia ambientalista no Brasil, sob a Ditadura Militar nos anos 1970, e as primeiras discussões que foram realizadas no plano internacional e interno. Reforça, ainda, a resistência das instâncias governamentais em torno desse debate, uma vez que o milagre econômico do início dos anos 1970 e o crescimento do PIB ajudavam a manter o regime ditatorial no poder e necessitavam da exploração do ambiente para manter essa economia intacta.

O décimo artigo é "Entre o urbano e o rural: fotografias de paisagens das cidades do Vale dos Sinos na Primeira República" do Me. Alex Juarez Müller, professor da rede municipal de ensino de Gramado, RS. Aborda o conceito de modernização urbana, durante o período da República Velha (1889-1930), através de fotografias 
que foram tiradas nas cidades de São Leopoldo, Novo Hamburgo e Taquara. Essas fotografias revelam as modificações da paisagem urbana que ocorreram no período através da influência do modelo europeu de organização do espaço.

O décimo primeiro artigo é "Potencialidades de pesquisa em História Ambiental e a questão indigena" da Me. Angela Rebelo da Silva Arruda, aluna de doutorado do Programa de Pós-Graduação em História da Universidade Federal do Amazonas (Ufam). Este artigo traz uma exploração das possibilidades da história ambiental especialmente voltada para a questão indígena no Brasil. A autora aponta, portanto, para uma série de dilemas ambientais encontrados no país devido à colonização predatória que foi empreendida na formação histórica do povo brasileiro e possiveis formas de realizar pesquisas nesse entorno.

Ainda, o dossiê traz a resenha de Bianca Letícia de Almeida, aluna de mestrado do Programa de Pós-Graduação em História da Universidade Federal de São Paulo (Unifesp), sobre o livro The Environmental Humanities: A Critical Introduction, escrito por Robert S. Emmett e David E. Nye e publicado em 2017, ainda sem tradução para a lingua portuguesa.

Esperamos que este dossiê temático possa publicizar novas perspectivas no campo de história ambiental, assim como fomentar a interdisciplinaridade que tem sido implementada de forma tão essencial nas pesquisas dessa área. A diversidade de artigos aqui encontrados, com abordagens desde a História das Ideias, passando pela luta pela terra, pela análise política, pela militância ambiental, pela análise de uma catástrofe ambiental como trauma coletivo, provam essa premissa e ajudam a mostrar a pujança do ambiente e da paisagem como objetos para a historiografia. Pois é ao ver o "outro", não importando que tipo de alteridade, que conseguimos enxergar melhor a nós mesmos.

\section{Referências}

BUBLITZ, Juliana. O recomeço na mata: notas para uma história ambiental da colonização alemã no Rio Grande do Sul. História Unisinos, São Leopoldo, v. 12, n. 3, p. 207218, set./dez. 2008. https://doi.org/10.4013/htu.20083.02
CARVALHO, José Murilo. O motivo edênico no imaginário popular brasileiro. Revista Brasileira de Ciências Sociais, São Paulo, v. 13, n. 38, out. 1998. https://doi. org/10.1590/S0102-69091998000300004

CHAKRABARTY, Dipesh. The climate of history: four theses. Critical Inquiry, Chicago, v. 35, n. 2, p. 197-222, inverno de 2009. https://doi.org/10.1086/596640

LE ROY LADURIE, Emmanuel. Présentation. Annales. Économies, Sociétés, Civilisations, 29 année, n. 3, 1974. https://doi.org/10.1017/S0395264900169409

NASH, Roderick Frazier. Wilderness and the American Mind. New Haven and London: Yale University Press, 2014.

PADUA, José A. Herança romântica e ecologismo contemporâneo - Existe um vínculo histórico? Varia Historia, Belo Horizonte, v. 21, n. 33, 2005. https://doi. org/10.1590/S0104-87752005000100004

RÜCKERT, Fabiano Q. O saneamento e a politização da higiene no Rio Grande do Sul (1828-1930). 276f. 2015. Tese (Doutorado em História) - Programa de Pós-Graduação em História. Universidade do Vale do Rio Caí, São Leopoldo, 2015.

\section{Caio Flores-Coelho}

Mestre em Antropologia Social pela Universidade Federal do Rio Grande do Sul (UFRGS), em Porto Alegre, RS, Brasil; doutorando em História pela Pontificia Universidade Católica do Rio Grande do Sul (PUCRS), em Porto Alegre, RS, Brasil; professor auxiliar do Curso de Licenciatura em História do Instituto Superior de Educação Ivoti (ISEI), em Ivoti, RS, Brasil; professor-tutor do Eixo de Humanismo Social da Universidade do Vale do Rio dos Sinos (Unisinos), em São Leopoldo, RS, Brasil; professor de História do Colégio Sinodal, em São Leopoldo, RS, Brasil.

\section{Paula Tatiane de Azevedo}

Mestre em Ensino de História pelo Instituto de Filosofia e Ciências Humanas da Universidade Federal do Rio Grande do Sul (IFCH/UFRGS), Porto Alegre, RS, Brasil; doutoranda em História pela Pontificia Universidade Católica do Rio Grande do Sul (PUCRS), em Porto Alegre, RS, Brasil.

\section{Lucas de Oliveira Klever}

Mestre e doutorando em História pela Pontifícia Universidade Católica do Rio Grande do Sul (PUCRS), em Porto Alegre, RS, Brasil.

\section{Endereço para correspondência}

Caio Flores-Coelho

Instituto Superior de Educação Ivoti

Rua Pastor Ernesto Schlieper, 200

Sete de Setembro, 93900000

Ivoti, RS, Brasil 